\title{
Los comienzos del quidditch en Argentina. Un deporte para «mis chicos»
}

\author{
The beginnings of Quidditch in Argentina: A sport for "my kids"
}

\section{David Ibarrola*}

Licenciado y profesor en Ciencias Antropológicas en la Universidad de Buenos Aires (UBA), con orientación Sociocultural. Desde 2020 es becario interno doctoral de CONICET en el Instituto de Investigaciones Gino Germani, con un proyecto titulado «De la lectura al asociativismo deportivo: sentidos y prácticas en el quidditch argentino».

•david.ibarrola92@gmail.com http://orcid.org/0000-00015154-4938

\section{RECIBID 0: 15.3.2021}

\section{Resumen}

El quidditch es una práctica deportiva inspirada en la exitosa saga literaria de Harry Potter, obra de la británica J. K. Rowling. Creado por un grupo de estudiantes universitarios estadounidenses, ha logrado en poco tiempo una expansión de características planetarias; cuenta con organismos nacionales e internacionales y competencias en todos los continentes. El propósito de este trabajo es abordar las interacciones entre las escalas locales y globales. Específicamente, se explorarán los orígenes de la práctica en Argentina, hacia 2006, que surgió en el marco de un club de fans de Harry Potter, destinada a cierto público y a condiciones locales particulares. Para lograr estos propósitos apelaré a entrevistas en profundidad con distintos actores y a producciones académicas previas en la materia.

Palabras clave: deporte, literatura, Argentina.

\section{Abstract}

Quidditch is a sport inspired by the successful literary saga Harry Potter, the work of British J.K. Rowling. Created by a group of American university students, it has achieved rapid expansion worldwide in a short time, giving rise to national and international organizations and competitions on all continents. The purpose of this work is to address local/global interactions. The origins of the practice in Argentina will be explored. They can be found around 2006, in the context of a Harry Potter's fan club aimed at a particular audience, under 
specific local conditions. To achieve these purposes, in-depth interviews with different actors have been carried out, and previous academic productions on the subject were consulted.

Keywords: sport, literature, Argentina.

\section{Introducción}

En las últimas décadas se han producido importantes cambios en la sociedad industrial, los cuales deben considerarse al momento de pensar la relación entre lo local y lo global. En este sentido, Appadurai (2001) proporciona una serie de claves interpretativas de la llamada globalización. El autor señala una era de quiebre en las relaciones intersocietales. Dos factores son fundamentales: las crecientes migraciones y el papel de los medios de comunicación, que afectan el «trabajo de imaginación» propio de la subjetividad moderna. Un rasgo central de este período es el agotamiento del Estadonación como eje de los grandes problemas contemporáneos, producto de la inestabilidad de las comunidades locales. A partir de esto, cobran importancia dos factores: por un lado, la fuerte agencia de los consumidores de los medios y la cultura de masas, y, relacionado con ello, la aparición de fenómenos denominados hermandades trasnacionales. Se trata de comunidades capaces de pasar de la imaginación compartida a la acción colectiva, producto de la experiencia en torno a estos medios de comunicación.

Al respecto, Appadurai (2001) señala que el impacto y la apropiación de la globalización son diferentes según las regiones del planeta, con tensiones entre la homogeneización y la heterogeneización. Así, como señala Rivera Gómez (2012), para pensar fenómenos como los fans es necesario contemplar la globalidad, pero también utilizar un enfoque que ancle en la dimensión territorial. Estos fenómenos adoptan características específicas relacionadas con sujetos socialmente contextualizados, que se apropian localmente de los productos de los medios de comunicación globales, los interpretan, evalúan, repiensan y reelaboran, de acuerdo a sus fines y sentidos particulares (Abu Lughod, 2001). Remarcarlo es importante para comprender el objeto de este trabajo: el quidditch.

Nos referimos a una práctica deportiva creada en 2005 en Estados Unidos, que al día de la fecha cuenta con equipos y asociaciones en todos los continentes. Este deporte toma la denominación de una actividad del mismo nombre que aparece en la saga literaria de Harry Potter, escrita por la británica J. K. Rowling, que nos introduce en la historia de un joven huérfano que a los once años se entera de que es un mago y ha sido admitido en una escuela de magia, Hogwarts. Allí, además de desenvolverse la mayor parte de la trama, se nos presenta el deporte mágico más popular: el quidditch. Este se 
juega sobre escobas voladoras y con pelotas encantadas. La inexistencia de magia que pueda hacer volar los objetos fue uno de los grandes desafíos que tuvo el grupo de estudiantes universitarios estadounidenses que se propuso adaptar el quidditch en 2005, mientras buscaba cómo pasar el tiempo en el campus, tal como señala Adam Cohen (2013) en su tesis doctoral.

En Argentina, aunque comenzó a jugarse hacia el año 2006, son casi inexistentes los trabajos académicos que abordan el fenómeno. El solitario aporte de Paula Cuestas (2016) invita a pensar la relación entre lo local y lo global en el quidditch argentino. Retomando algunas de las premisas señaladas en el primer párrafo de este trabajo, la autora analiza las interconexiones entre las escalas para dar cuenta de apropiaciones particulares de este fenómeno mundial, resultado de las condiciones locales. Estas apropiaciones toman la forma de cantos de las hinchadas de fútbol argentino y la adaptación de las pelotas a las disponibles en el mercado local; un proceso de recontextualización (Giulianotti y Robertson, 2009). Esto se evidenció especialmente a partir de 2013, cuando el quidditch argentino, a través de su asociación nacional, ${ }^{1}$ buscó acercarse a la International Quidditch Association (IQA), ${ }^{2}$ que lo influyó profundamente. La membresía le exigió adoptar el reglamento de la IQA en las competencias oficiales, lo que dio lugar a debates que tensionaron las formas de jugar argentinas con los mandatos internacionales, como en la demorada implementación del tackleo (Ibarrola, 2018).

En este artículo, intentaré profundizar los aportes de Paula Cuestas. Lejos de la actual «profesionalización» del quidditch (Cuestas, 2016), me situaré en el 2006. En ese año, un grupo de miembros del Círculo de Lectores de Harry Potter (CHP), un fan club de la Ciudad de Buenos Aires, comenzó a pensar en la posibilidad de incorporar el quidditch como una de sus actividades e intentó emular las experiencias extranjeras ya existentes ¿Cómo se dio esta relación entre lo local y lo global en los primeros tiempos del quidditch? ¿Se puede hablar de apropiación y resignificación? ¿Cómo se vincula con la configuración actual de la práctica?

Para abordar estos interrogantes, junto con la discusión de literatura sobre deporte y comunicación, apelaré a una serie de entrevistas realizadas con distintos jugadores activos e inactivos de este deporte, lo que se complementará con conclusiones presentadas en trabajos previos sobre el quidditch argentino. Se trata de breves investigaciones que combinaron entrevistas, encuestas, observaciones participantes y discusión teórico-conceptual, las cuales permiten establecer diálogos y referencias con el contenido tratado en este trabajo. 


\section{Los frikis no se andan golpeando}

Una lectura atenta de los momentos en que los libros de Harry Potter nos sitúan en partidos de quidditch nos permite dimensionar la violencia de esta actividad. El protagonista se fractura el brazo, cae desde las alturas y pierde el conocimiento por un golpe en la cabeza, entre otras cosas. El quidditch enfrenta a dos equipos ${ }^{3}$ integrados por siete jugadores montados en escobas voladoras. Tres jugadores, llamados cazadores, ${ }^{4}$ deben marcar tantos con una pelota (quaffle) en la portería rival, representada por tres postes muy elevados con un aro en su extremo. Un guardián los vigila y es su última defensa. La tarea de los cazadores se ve dificultada por dos jugadores que, armados con bates, les lanzan pelotas bludger (las cuales vuelan libremente) para derribarlos de la escoba. Un séptimo jugador debe atrapar una pequeña pelota voladora (snitch), lo cual decreta el final del juego.

Ahora bien, en un trabajo previo, Ibarrola (2020) señala el fuerte énfasis en la rudeza, el contacto físico, la fuerza, la preparación, la exigencia y el movimiento permanente con los que los jugadores argentinos caracterizan su práctica. La elección de estos aspectos del quidditch puede estar relacionada con la imagen tradicional del fanático como antagónica de la actividad física, tal como sugiere un trabajo del mismo autor (Ibarrola, 2019). «La concepción general es que un friki no se va a andar golpeando», comenta Gonzalo ${ }^{5}$ en una entrevista. Con independencia de las percepciones de los actores, la violencia del juego y las frecuentes lesiones son un elemento que efectivamente llama la atención de los espectadores en cada una de las prácticas y torneos de quidditch. De acuerdo con una encuesta realizada en el año 2019, el $52 \%$ de los jugadores afirmaba haberse lesionado por lo menos una vez jugando este deporte (Ibarrola, 2019).

Es que el quidditch se presenta actualmente como una amalgama entre diversos deportes de contacto, como el rugby, la lucha y el handball, junto con el dodgeball (quemado). Se trata de un deporte mixto, que incluye un máximo de cuatro jugadores por equipo (cada uno tiene siete integrantes) que se perciban con el mismo género, que puede ser masculino, femenino o no binario (Segrave, 2015). Todos los jugadores llevan entre sus piernas un palo de PVC, que debe ser sostenido con una mano en todo momento y emula la escoba de la versión original.

El objetivo de cada equipo es marcar tantos en la portería rival, compuesta por tres aros sostenidos por postes. Los encargados de dicha tarea son los tres cazadores del equipo, quienes deben meter la pelota quaffle (un balón de voley) dentro de los aros.

3 Vale la pena aclarar que la composición de género de los equipos es libre; puede haber equipos de un solo género o mixtos.

4 Se pondrán en cursiva aquellos términos nativos.

5 Todos los nombres utilizados aquí son ficticios. 
Su tarea se verá obstaculizada por otros jugadores, los golpeadores. Se trata de un par que lanza balones de dodgeball (hay tres en el campo y representan a las bludger) a los jugadores rivales para quemarlos. Una vez quemado, el jugador debe volver a su portería, tocar los aros y reintegrarse al juego. Un sexto jugador es el guardián, quien vigila su valla y tiene inmunidad en su pequeña área. Además, puede participar en maniobras ofensivas como los otros cazadores. Cuando se cumple cierto tiempo de juego, ingresa a la cancha un jugador neutral (de ninguno de los equipos involucrados) vestido de amarillo, llamado snitch runner. Este lleva colgada en la cintura una pelotita amarilla que representa a la snitch, la cual debe ser atrapada por el buscador, que es el séptimo jugador del equipo y permanece fuera del campo hasta el ingreso del snitch runner. Una vez conseguido esto, el partido puede concluir o continuar, según los deseos de los equipos. ${ }^{6}$

Una lectura atenta de los reglamentos vigentes para las competencias oficiales (International Quidditch Association [IAQ], 2020) ofrece un panorama del tratamiento de las distintas formas de contacto, tales como cargas, empujes, abrazos, tackles, bloqueos y pantallas. Como veremos a continuación, existe una clara diferencia entre esta configuración y la de los primeros tiempos del quidditch argentino. El quidditch actual, adaptado cada día más a los reglamentos internacionales y valorado por sus practicantes por la violencia y el despliegue físico que conlleva, ha generado impresiones negativas entre los impulsores originarios de esta actividad en Argentina. Según Yolanda, una de ellos, el nivel de violencia actual del quidditch argentino es incompatible con el ideario original del deporte, fuertemente influido por el mundo de los fans de Harry Potter. Ese período inicial del quidditch en el país será el objeto del siguiente apartado.

\section{Un club de fans}

El CHP surgió en la Ciudad de Buenos Aires en 2005. Como creación de un grupo de lectores de Harry Potter, es el resultado de la búsqueda de nuevos espacios para desarrollar su fanatismo (Cuestas, 2012) y toma la forma de un club de fans que intenta replicar distintos aspectos de la saga literaria. Uno de ellos es la mencionada escuela de magia Hogwarts, cuyos estudiantes se dividen en cuatro grandes casas: Gryffindor, Hufflepuff, Ravenclaw y Slytherin. En el libro, estas compiten entre sí mediante un sistema de puntos obtenidos por el desempeño en clase, la disciplina y el quidditch escolar. El CHP imita este ordenamiento; divide a sus miembros de igual modo y compite en los 
mismos términos. En este marco, hacia 2006, quienes organizaban el club de fans tuvieron la idea de agregar a los concursos de trivias sobre la saga y las clases ya existentes una adaptación del deporte mágico.

Yolanda fue miembro de la casa Hufflepuff durante la primera década de los 2000. Recientemente tuve la ocasión de conversar en profundidad con ella. Es la principal artífice del quidditch en Argentina para el CHP y afirma estar orgullosa «de poder haber traído un pedazo de magia». Nos apoyaremos mayormente en su relato (aunque no en forma exclusiva) debido al rol determinante que tiene para nuestro objeto de estudio. El relato de Yolanda nos remonta a los comienzos del CHP, en 2005. Nos situamos en el momento en que el grupo organizador preparaba las reuniones para ese año. Allí, en la planificación, surgió la idea de agregar quidditch a las competencias que estructuraban el club. La aparición de este deporte aparece subsumida en las actividades de ese espacio y su dinámica (Ibarrola, 2020). La dinámica y el calendario del CHP determinarían los tiempos de juego de este deporte, tal como ocurría en el libro: los equipos jugaban solo tres partidos al año. De este modo lo recuerda Guillermo: «Era un juego más orientado a revivir la saga y a jugar a que estábamos en la saga que un deporte serio». Como veremos, el quidditch no conocería una existencia independiente hasta 2010.

De acuerdo a lo narrado por Yolanda, el primer paso fue que cada casa comenzara a registrar cuántos de sus miembros estarían dispuestos a jugar. La respuesta de los participantes del club fue más que positiva. El anuncio de la inserción del quidditch en el CHP fue realizado un año después, en 2006: el primer evento tendría lugar en la tercera reunión de ese año. La siguiente misión fue para los jefes ${ }^{7}$ de las casas, quienes debieron encargarse de preparar al equipo representativo, entrenando en los parques. Pero entre estas instancias se estaba poniendo en juego la facultad creadora: había que determinar la forma en que se jugaría y establecer las reglas, entre muchas otras tareas elementales.

Diversos autores señalan que ciertas obras adoptan el estatus de narrativas transmedia debido a su capacidad de dispersarse a través de distintas plataformas mediáticas, lo que genera un entretenimiento coordinado y unificado. De acuerdo con Melle y Pardo (2016), Harry Potter es un buen ejemplo de ello. No solo hablamos de películas y videojuegos, sino también de una serie de obras literarias que complementan los siete libros originales. ${ }^{8}$ Uno de ellos es Quidditch a través de los tiempos (Rowling, 2001). En él conocemos el origen (en el mundo mágico) del deporte, sus principales equipos, re-

7 De acuerdo con Aller (2020), se trata del autodenominado staff del club, el cual se encarga de organizar la actividad. También estaban divididos por casas.

$8 \quad$ Harry Potter y la piedra filosofal (1997), Harry Potter y la cámara secreta (1998), Harry Potter y el prisionero de Azkaban (1999), Harry Potter y el cáliz de fuego (2000), Harry Potter y la Orden del Fénix (2003), Harry Potter y el misterio del príncipe (2005) y Harry Potter y las Reliquias de la Muerte (2007). 
glas e hitos. Este pequeño libro, cuya aparición fue contemporánea al lanzamiento mundial de la primera película (2001), es señalado por Yolanda como una de sus principales fuentes de inspiración.

Sin embargo, no debemos olvidar que estamos ante un miembro del fandom ${ }^{9}$ de Harry Potter, en cuya constitución Roberta Aller (2020) señala acertadamente el importante rol de internet. Ella explica que este medio permitió que muchos fans se conociesen y comenzasen a comprender que no estaban solos en su afición. Espacios como los foros y los blogs se constituyeron en instancias de divulgación y creación de una comunidad. En el caso del quidditch argentino, fueron una gran fuente de ideas e información para Yolanda, resultado de una pormenorizada búsqueda allí y en la web. El punto de partida para esta investigación fue el rumor de que se jugaba quidditch en algunas partes del mundo, como España o Estados Unidos. La punta fue uno de los miembros del grupo organizador del CHP, que por entonces era dueño de una muy conocida página web: harrylatino.com. Él fue quien orientó la pesquisa de Yolanda, que se focalizó en Barcelona y en ciertas universidades estadounidenses que divulgaban los primeros pasos de este deporte en la red. A partir de allí comenzó la búsqueda de reglas, pelotas y el análisis de cómo incorporar ciertos aspectos observados y leídos. Yolanda encontró segmentos de videos y artículos donde se informaba el modo en que se jugaba en esos países, los cuales le dieron una perspectiva amplia.

Desgraciadamente, no he podido acceder a esos valiosos materiales. El registro fílmico y escrito encontrado que nos puede aproximar al deporte en estos países comienza en 2008 y presenta muchas similitudes con la configuración actual del quidditch. Aquella modalidad de juego también era mixta. Ya existía la snitch encarnada en un hombre «vestido de amarillo con una pelota de tenis pegada en la espalda» (Maponto, 2008). También se establecía la escoba entre las piernas como un requisito para poder jugar, una pelota de vóley como quaffle, y los golpeadores arrojaban balones de dodgeball-bludgers para estorbar el camino de los cazadores hacia la portería ajena (Opperman, 2008). En este punto, cuando eran impactados por la bludger, en vez tocar sus aros para volver al juego, debían dar una vuelta trotando a la zona de los aros. En algunos videos se pueden oír las exclamaciones y los lamentos del público ante las caídas, fuertes golpes y choques de los jugadores (Daily Hampshire Gazette, 2008). Este formato de juego se vio reflejado en el primer reglamento registrado, en el cual se afirma que, aunque no se permiten las faltas excesivas, el contacto físico es una parte fundamental del juego, por lo que las reglas son «bastante abiertas» (Benepe, 2008). Una lectura de dicho documento nos muestra que el agarre, el golpe con los hombros, el empujón y el tackleo eran

Siguiendo a Aller, entiendo este fenómeno como «grupos de personas que se sienten parte de una comunidad que interactúa alrededor de un objeto de interés (persona, texto, etcétera) y que comparten un universo simbólico común» (Aller, 2020, p. 6). 
acciones legítimas. Estamos frente a una creación que es el resultado de la búsqueda de un deporte adecuado para los estándares del ámbito universitario estadounidense.

\section{Un deporte de caballeros para «mis chicos»}

La preocupación por la violencia en el deporte ha sido un tema recurrente en las ciencias sociales especializadas. En el clásico Deporte y ocio en el proceso de la civilización, de Elías y Dunning (1992), el tema es abordado en profundidad. Allí brilla el contraste entre los juegos de la antigüedad y el deporte actual: mientras que los primeros admiten mayor violencia, brindan menor seguridad física a los participantes y poseen reglas dictadas por los particularismos y las costumbres, el segundo presenta las características opuestas; es, sobre todo, una actividad altamente especializada, institucionalizada y regulada. Los autores hablan de una «civilización» de los juegos que implicó la aparición de reglas escritas que controlaran y sancionaran el uso de la fuerza, a la vez que promovieran el autocontrol de los participantes en este sentido. El cambio en los pasatiempos tradicionales, denominado proceso de deportivización, estuvo enmarcado en una tendencia general en la Europa occidental del siglo XV a reducir la tolerancia ante los actos violentos como una fuente de satisfacción en sí misma, y al crecimiento de restricciones y reglamentaciones de la conducta, producto de una serie de sucesos políticos de pacificación interna ocurridos en Gran Bretaña. Así, el deporte es para Elías y Dunning (1992) una expresión ritualizada y socialmente aceptada de la violencia física, controlada por reglas y convenciones; una lucha fingida donde sí se pueden liberar, canalizar y expresar emociones no bien vistas por la sociedad. Implica tensiones controladas y bien atemperadas, en las que se reduce al mínimo la posibilidad de un daño serio.

La idea de violencia está presente en las conclusiones a las que arribó Yolanda tras su investigación. Aparece empleada con frecuencia en las experiencias analizadas y la llevó a «pensar las reglas de manera tal que sepa que nadie se va a golpear ni lastimar por jugar con nosotros». Por tanto, orientó la creación de un deporte «no muy de contacto», que se asimile al handball escolar. Además, «la versión estadounidense me había parecido para jóvenes-adultos, una onda más fútbol profesional que deporte escolar». Su propósito manifiesto era que «los chicos llevaran una conducta que los [hiciera] sentir bien por competir sanamente». La premisa esencial era la de «un deporte de caballeros» y «just for fun», según las palabras de la creadora del quidditch argentino, en lo que parece ser una referencia a la clásica ética del deporte, en que lo importante era la participación en las «batallas» regladas, el disfrute de su tensión y emoción, y no el triunfo (Elías y Dunning, 1992).

La idea de jugar violentamente está por fuera de la lógica de Yolanda: el fanático de Harry Potter (habitué del CHP) es, desde su punto de vista, una persona creativa y 
con imaginación, que buscará soluciones a sus problemas e inconvenientes. El juego brusco sería propio de los muggles ${ }^{10}$ y genera bronca en la entrevistada, quien lo cataloga como comportamiento de barrabrava: impropio del verdadero fan y del jugador/deportista. La significación negativa de la violencia es más clara aún en el discurso de Yolanda cuando habla de los actuales jugadores de la Asociación de Quidditch Argentina (AQA), a quienes llama "profesionales». Muchos de ellos participan en los partidos que organiza el CHP en sus competencias internas, tal como sucedía en 2006. Para la creadora de la actividad, estos «contaminan» con violencia los encuentros de quidditch. ${ }^{11}$ Así, el «profesionalismo», la ambición por el triunfo y la competencia, tal como señalan Elías y Dunning (1992), sientan las bases para el uso indebido de la violencia en las competencias del CHP y la emergencia de conflictos que han llevado a que durante un tiempo esta actividad fuera suspendida.

Ahora bien, ¿cuál fue el modo que encontró Yolanda para enfrentar la violencia observada en su investigación? La respuesta hallada es la configuración de un quidditch para el CHP claramente regulado. Así lo recuerda una jugadora de aquella época: «Tenía un montón de reglas puntuales que lo hacían estar a uno atento todo el tiempo». Un deporte con reglas claras: «Los organizadores, los jueces de línea, tenían muy claro que no se podían dejar pasar las cosas. Tenían muy claro que no se podían ignorar los atropellos. Te mandabas una; a la primera, advertencia, a la segunda ya no».

La interpretación sobre la violencia estaba fuertemente condicionada por el factor etario. Estos elementos combinados dan forma a parte de la lógica que orientó la creación de esta primera versión del quidditch argentino. Según Yolanda, había participantes (a quienes llama recurrentemente «mis chicos» debido a que era jefa de su casa) de 11 años jugando junto con otros de 17. Esto volvía aún más necesario el control de la violencia que pudiera ejercerse. La preocupación era clara: si se producía una lesión, ¿quién respondía ante los padres?

«No estábamos reconocidos oficialmente, éramos un grupo de personas que se juntaban a hacer cosas de Harry Potter. No éramos una escuela, que tiene un seguro». En este contexto, Yolanda afirma que pensó en un deporte que pudiera ser disputado por ella, que tenía 27 años, junto con esos niños y adolescentes. «Si yo podía jugar, que no tenía estado físico ni hacía nada de actividad física desde mucho tiempo atrás, entonces estaba bueno y sabía que a nadie le iba a pasar nada». Nuevamente se marca la contraposición con el quidditch de la AQA: «Hoy, nada que ver. Hoy necesitás un estado físico importante». Tampoco debemos olvidar la intención del CHP de recrear la escuela Hogwarts, con lo que colaboraba la edad de la mayoría de los miembros del club. Así, la

10 Modo en que se refieren a las personas no mágicas.

11 Estas se realizan con el reglamento de la AQA, pero con algunas adaptaciones que limitan los contactos físicos. 
referencia de Yolanda fue el quidditch de la escuela Hogwarts y no el profesional de los libros. Ella nos remite al cuarto libro de la saga, en el que los protagonistas asisten al mundial de quidditch y describen lo visto allí como un deporte totalmente distinto al que juegan en la escuela. Esto marca aún más el contraste con lo que considera una versión «estadounidense» para jóvenes-adultos, que conoció en su investigación inicial. Las reuniones del CHP, explica Yolanda, eran escolares, no deportivas; por tanto, la «adaptación» debía ser más «tranquila».

Es interesante prestar atención a la forma que adoptó esta primera versión del quidditch argentino, catalogada por Yolanda como «adaptación propia». Se trató de un proceso trabajoso y ambicioso que puso toda su creatividad en juego. En este punto seguiremos apoyándonos en su relato, pero también apelaremos al reglamento escrito que ella nos proporcionó. Una rápida ojeada revela que los jugadores también llevaban una escoba entre las piernas y cumplían, a grandes rasgos, las mismas funciones y posiciones que en el libro. Los equipos, de siete jugadores, eran conformados libremente en cuanto al género, como en el libro.

Sin embargo, al llegar al juego de snitch, la cuestión se vuelve interesante. Al parecer, la edad no fue el único elemento del universo local que condicionó la configuración del quidditch; otra gran cuestión fue la infraestructura. Las reuniones no tenían lugar en grandes predios deportivos, aptos para la actividad física; se realizaban en el Centro Cultural Mariano Moreno, un espacio cerrado con piso de cemento y un anfiteatro que rodeaba el campo de juego. Este último fue utilizado creativamente para la snitch. Una caña de pescar, una fina tanza enganchada con un clip roto a una pelota de telgopor ${ }^{12}$ pintada de dorado y con una «alitas» adheridas (emulando el aspecto de la snitch de libros y películas) fueron los elementos utilizados para recrear la pequeña pelota. Quien manejaba estos instrumentos debía ser un jugador neutral, que no integrara ninguna de las casas involucradas en el partido. Este introducía y retiraba «oportunamente» la pelota del campo, lo cual hacía que el buscador debiera entrar y salir del mismo modo.

El árbitro sonaba su silbato cuando la pelota aparecía y comenzaba la persecución: la snitch era zarandeada, esquivaba a los jugadores y finalmente era sujetada por el buscador (lo que concluía el juego). La identidad de nuestro proto-snitch runner era un enigma para los jugadores, ya que en el anfiteatro estaban todos los miembros del grupo organizador del CHP que no se encontraban arbitrando. ${ }^{13}$ Así, esta original mecánica comparte con la versión actual el no ingreso inmediato de la snitch, pero difiere totalmente en lo demás. Esto es lógico, debido a que el quidditch actual de la AQA se disputa en predios al aire libre. En conjunto, el mecanismo ideado para la snitch era catalogado

12 Nombre con el que se conoce en Argentina al poliestireno expandido.

13 Al igual que quien manejaba la snitch, las autoridades arbitrales debían ser de las casas no involucradas en el partido. Estas autoridades eran los réferis, acompañados por los jueces de línea. 
como «mágico» por Ezequiel, uno de los primeros buscadores del quidditch argentino, por la casa Ravenclaw.

La reglamentación de otras posiciones en cancha ilustra a la perfección el cuidado por evitar la violencia. Para el juego de golpeadores se implementaron como bludger pelotas con «pinchecitos» que eran «de goma, bien de juguete [...] sobre todo para aliviar también los golpes; te pegaba eso y no pasaba nada». En esta versión eran dos, y no tres como en la actual. Los dos golpeadores eran divididos en «ofensivo» y «defensivo». Este último tenía inmunidad para evitar que el equipo quedara desprotegido. El propósito de esta división, una vez más, era evitar la violencia. Nos dice Yolanda: «Dos golpeadores haciendo lo mismo, reventar al otro equipo para que no hiciera el gol, era muy fuerte; en un recinto cerrado y chico, era mejor jugarlo con una sola persona en esa función».

Por eso, el golpeador defensivo podía utilizar un bate para repeler las pelotas que amenazaban a sus compañeros de equipo, pero no podía atacar ni tocar la bludger con la mano. El golpeador ofensivo podía soltar las manos de la escoba (lo cual estaba prohibido para el resto de los jugadores), tomar con una de ellas el bate y «con la otra lanzarse la pelota y pegarle». Otra regla para los golpeadores era que solo podían moverse en una de las mitades, izquierda o derecha, del campo, y atacar a los cazadores y el guardián que estuvieran en la zona contraria. Solo tenían permitido cruzarse a la otra mitad si todos los cazadores rivales estaban de su lado de la cancha. La presencia de este sistema de bateo para los golpeadores es considerada una concesión para que el espectáculo visual fuera «más parecido a Harry Potter que una comodidad deportiva». Esto era visto como algo «ridiculísimo» e imposible de hacer por muchos jugadores como Lucas, que luego conformaron la primera asociación nacional de este deporte e impulsarían un acercamiento a los reglamentos internacionales.

A lo largo de este apartado, hemos señalado con insistencia la intención de Yolanda de evitar la violencia desmedida, pero el lector podrá considerar que la presencia de bates en un espacio cerrado conspira contra dichas aspiraciones. Esto no es así, ya que el bate era tallado sobre... un ¡flota-flota! ${ }^{14}$ El mismo procedimiento era utilizado para las escobas, también pintadas de marrón.

En el caso de los cazadores, para la quaffle se utilizaba una pelota desinflada (no específicamente de vóley) a fin de facilitar el agarre. Se reglaba un sistema de mínimo dos pases para poder marcar un tanto, con el fin de estimular el juego en equipo, la comunicación y el uso de señas. Yolanda se inspiró para esto en el vóley. Asimismo, se establecía una singular reglamentación: cuando el cazador perdía la quaffle, el otro equipo la recuperaba automáticamente. Esto también evitaba potenciales choques cuando esa pelota quedaba suelta en el campo y varios jugadores rivales se lanzaban a 
disputarla. Si los cazadores eran golpeados por la bludger, estos debían detener la jugada, ir hacia la pared del «estadio», tocarla y volver a ingresar. Con respecto a sus desplazamientos, se diferenciaban «tipos de vuelo», elemento totalmente ausente en la configuración actual del quidditch. Estos eran «erguido» y «agachado», a veces llamados «rápido»y «lento». Es decir que había que correr agachado y caminar de forma erguida.

Había menos posibilidades de que los chicos se golpearan si iban en vuelo lento. Cuando ves a un tipo que viene corriendo y agachado, y estás medio frenado, te corrés porque te lleva puesto [...] el que viene embalado no tiene por qué estar mirando a los que están parados.

$\mathrm{Al}$ parecer, esta propuesta fue un éxito y a la dinámica del CHP se le agregaron reuniones específicas de quidditch en las que se jugaban los partidos del fixture. A su vez, se invitaba a aquellos miembros de las casas que no jugaban a realizar acciones de aliento, como concursos de porristas, que también sumaban puntos para la competencia entre casas.

Este quidditch fue el punto de partida, el antecedente directo del quidditch argentino actual, que tuvo su gran hito en 2010, cuando hizo su aparición la Federación Argentina de Quidditch (FAQ), antecesora de la actual AQA. La FAQ fue creada por miembros del CHP que deseaban jugar al quidditch con mayor frecuencia. Se trata de un momento clave en la historia de este deporte, ya que se abre a la posibilidad de que lo jueguen personas ajenas al mundo de los fanáticos de Harry Potter: «Esto era para cualquiera que quisiera jugar, no importaba si sabías o no jugar al quidditch, si te gustaba o no Harry Potter, si habías visto el deporte y te había parecido copado o interesante». A su vez, este hecho expresa el entendimiento de la dimensión global del quidditch por los fundadores de la FAQ: de acuerdo con Camila, una de las primeras jugadoras de la FAQ, el propósito de crear esta asociación era disputar el mundial de la disciplina, para lo que se conformó una selección llamada los Wild Tigers. Sin embargo, estos no solo no viajaron, sino que jamás existieron como equipo, y son recordados solamente como el nombre de la frustrada selección argentina de quidditch.

\section{Conclusiones}

Popple (2015) sugiere que la existencia de escobas voladoras representa, en el quidditch de la saga literaria, un suplemento necesario para que el tamaño y la velocidad de los jugadores sea menos importante que la estrategia y el talento. Es esto lo que posibilita el juego mixto, desde una perspectiva que parece coincidir con algunos señala- 
mientos nativos sobre las ventajas promedio de los cuerpos masculinos sobre los femeninos (Ibarrola, 2020). Pero no se debe interpretar esto como un cese de la violencia, sino como una «democratización» entre los géneros para acceder a ella y controlarla. Al fin y al cabo, si vemos la primera película de la saga, Harry Potter y la piedra filosofal (Colombus y Heyman, 2001), nos encontramos con un protagonista a punto de entrar a su primer partido y un capitán que intenta calmar sus nervios: «Tranquilo, yo estaba igual en mi primer partido [...] La verdad, no me acuerdo... Una bludger me golpeó la cabeza a los cinco minutos. Me desperté a la semana en el hospital».

Como hemos señalado, esta violencia parece haberse transferido también a la versión actual del quidditch en todo el mundo. Este factor es el eje sobre el que se estructura la concepción de quidditch descripta en este trabajo, el antecedente directo de la actividad independiente del mundo fan en Argentina. Al igual que en el caso del rugby presentado por Elías y Dunning (1992), un reglamento claro y estricto, que restringía y regulaba los movimientos de los participantes, aparece como la solución implementada por Yolanda ante las inquietudes despertadas por las versiones extranjeras de la actividad. La «irracionalidad» de la violencia fue el gran temor de la creadora del quidditch y por ello aboga actualmente para que no haya jugadores de la AQA en el CHP. ${ }^{15}$

Estos señalamientos no deben tentarnos a asociar de forma directa el peligro de la violencia con la apertura de este deporte al mundo «profesional», como lo hace Yolanda. La relación lejos está de ser lineal. Tomemos, por ejemplo, las escobas. En la primera versión las encontramos hechas de flota-flota, pero durante la FAQ se utilizaron escobas reales. Solo tiempo después, bajo la amenaza del peligro que tales objetos producían para la seguridad del jugador, fueron reemplazados por palos de PVC (Cuestas, 2016). Algo similar puede decirse sobre «la salida», esto es, el momento en que suena el silbato para que comience el juego. Hasta la última modificación del reglamento (IQA, 2020), ambos equipos se colocaban en lados opuestos de la cancha y corrían hacia adelante en busca de las pelotas, que estaban en el centro. Esta situación fue modificada recientemente, para evitar los frecuentes choques entre los jugadores, y actualmente los equipos no se enfrentan en este momento. Así, las formas violentas y peligrosas de juego aparecen y desaparecen de manera intermitente a lo largo de la breve historia de este deporte.

Ahora bien, de la violencia como observación clave de Yolanda sobre el quidditch mundial de entonces se desprende, en parte, el problema de la edad. Este, junto con la cuestión de la infraestructura, son dos grandes factores condicionantes. En la introducción se mencionó el trabajo de Rivera Gómez (2012), quien destacaba la necesidad de trabajar con fenómenos surgidos de los medios de comunicación, contemplando las dis- 
tintas escalas, pensando en sujetos socialmente contextualizados. Así, la población particular, los intereses de recrear la «magia» y las posibilidades materiales concretas contribuyeron también a configurar esta versión local del quidditch. De este modo, en el acto creativo que dio lugar a esta práctica, lo global apareció como portador de un factor negativo e incompatible con la situación local (una propuesta adulta y violenta), lo que dio pie a una resignificación que ha sido presentada aquí (una propuesta para «chicos» $\mathrm{y}$ «caballeros»).

Es clara, entonces, la agencia de los sujetos ante fenómenos de naturaleza global, que interpretan y evalúan de acuerdo a sus posibilidades particulares (Abu Lughod, 2001). Estos ponen en juego su capacidad de apropiación en cuanto consumidores (Grillo, et al., 2016) integrando de forma significativa el bien en su vida. Es esto lo que habilita la posibilidad de creación, cuando el consumo se entrelaza en la subjetividad de los actores. De este modo, la recepción se «convierte en una experiencia, en el sentido de romper, cuestionar, transformar, completar: dejar una impresión o una impronta» (Grillo, et al., 2016, p. 46). Así, las «evocaciones» de «una producción cultural penetran en la dimensión subjetiva, reformulan - y son reformuladas por- las representaciones y, adquiriendo una nueva forma, se convierten en nuevas claves en relación con las cuales el receptor interpreta el mundo y a sí mismo» (Grillo et al., 2016).

Lo descripto en este trabajo representó las condiciones y los elementos con los que contó la FAQ para organizar la actividad en Argentina. En este sentido, su fundador sostiene que la base no fue buena. Habiendo viajado a Estados Unidos, él destaca en ese país la condición atlética y deportiva, su «cultura» en el ámbito educativo. Caracteriza a los estadounidenses como especialistas en las carreras y los deportes de contacto, entre otras cosas. Ellos, sujetos con condiciones atléticas y competitivas, eran los que se sumaban al quidditch.

Esta situación difiere de la de Argentina, donde el quidditch es visto como una «ñoñada», algo de «nerds». «Acá tenés veinte pibes que corren tres cuadras y se mueren. Eso es lo que pasaba al principio, no aguantaban. Por eso poníamos un piso y un techo de tiempo». Tal situación llevó a modificar aún más el reglamento; por ejemplo, a acortar el juego de snitch, limitar el campo de acción y movimiento del snitch runner, evitar que el partido se alargue y los jugadores se cansen. Es decir, la adaptación local inicial, pensada para un grupo de jóvenes fans, que evitaba roces, golpes y limitaba la competencia («just for fun») tuvo consecuencias cuando el quidditch argentino decidió emprender una serie de adecuaciones a los reglamentos de IQA, proceso en el que encontró dificultades. Llegamos aquí al problema de la recontextualización planteado en la introducción. 


\section{Referencias bibliográficas}

Aller, R. (2020). ¿Entre fans y devotos? Prácticas, creencias y simbologías de culto en el fandom de Harry Potter (Tesis de licenciatura). Facultad de Filosofía y Letras, Universidad de Buenos Aires, Argentina.

Abu-Lughod, L. (2001). Dramas of nationhood: The politics of television in Egypt. Chicago: University of Chicago Press.

Appadurai, A. (2001). La modernidad desbordada. México: Fondo de Cultura Económica.

Cohen, A. (2013). The impacts and benefits yielded from the sport of quidditch (Tesis de doctorado). A\&M University, Texas, Estados Unidos.

Colombus, C. (productor) y Heyman, D. (director). (2001). Harry Potter y la piedra filosofal [Cinta cinematográfica]. Warner Bros., Heyday Films.

Cuestas, P. (diciembre, 2012). Mi mágico mundo: Una nueva mirada sobre los fanáticos de Harry Potter. Ponencia presentada en las VII Jornadas de Sociología de la UNLP, La Plata.

Cuestas, P. (mayo, 2016). De lectores, fans y jugadores de Quidditch: Recorriendo el mundo mágico de Harry Potter. Ponencia presentada en las VII Jornadas de Poéticas de la Literatura Argentina para Niñ@s, Ensenada.

Daily Hampshire Gazette. (2008, 28 de marzo). Muggle quidditch match at Amherst College [Archivo de video]. Recuperado de https://www.youtube.com/watch?

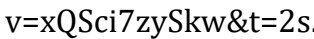

Elías, N., y Dunning, E. (1992). Deporte y ocio en el proceso de civilización. México: Fondo de Cultura Económica.

Giulianotti, R., y Robertson, R. (2009). Globalization and football. Londres: Sage.

Grillo, M., Papalini, V., y Benítez Larghi, S. (2016). El estudio sobre consumos culturales. En M. Grillo, S. Benítez Larghi y V. Papalini (coords.), Estudios sobre consumos culturales en la Argentina contemporánea (pp. 23-58). Buenos Aires: CLACSO.

Ibarrola, D. (diciembre, 2018). El desarrollo del quidditch en Argentina: Una primera aproximación. Ponencia presentada en las X Jornadas de Sociología, Ensenada.

Ibarrola, D. (agosto, 2019). Una discusión acerca de la conceptualización del quidditch: El caso argentino. Ponencia presentada en las XIII Jornadas de Sociología, Buenos Aires.

Ibarrola, D. (2020). Apuntes para pensar una relación entre quidditch y género. Revista Kula, 22, 27-37

Benepe, A. (2008). Intercollegiate quidditch rules and guide-book. Recuperado de https://www.usquidditch.org/files/IQA_Rulebook_1.doc.

International Quidditch Association. (2020). IQA Rulebook. Recuperado de https://iqasport.org/wp-content/uploads/2020/10/Rulebook-20.pdf. 
Maponto. (2008, 17 de octubre). Colegios y universidades se preparan para la «Segunda Copa Mundial de Quidditch». Recuperado de https://www.bloghogwarts.com/ 2008/10/17/colegios-y-universidades-se-preparan-para-la-segunda-copa-mundial-de-quidditch/.

Melle, M., y Pardo, A. (2016). Las narrativas transmedia en Harry Potter (Tesis de grado). Universidad de Santiago de Compostela, España.

Opperman, K. (2008, 18 de septiembre). Quidditch invasion. The Mac Weekly. Recuperado de https://themacweekly.com/63673/archive/quidditch-invasion/.

Popple, J. (2015). Embracing the magic: Muggle quidditch and the transformation of gender equality from fantasy to reality. En L. S. Brenner (ed.), Playing Harry Potter: Essays and interviews on fandom and performance (pp. 188-205). Jefferson: McFarland.

Rivera Gómez, E. (2012). Fans: Condiciones sociales e imágenes culturales en la conformación de la identidad (Tesis de licenciatura). Facultad de Ciencias Políticas y Sociales, Universidad Nacional Autónoma de México, México.

Rowling, J. (2001). Quidditch a través de los tiempos. Barcelona: Salamandra.

Segrave, J. (2015). Challenging the gender binary: The fictive and real world of quidditch. Sport in Society, 19, 1299-1315. 